\title{
Dramaturgi Media Sosial: Fenomena Penggunaan Fake Account Instagram Pada Penggemar K-POP Perempuan di Karawang
}

Social Media Dramaturgy: Phenomenon of Using Fake Instagram Account on Female K-POP Fans in Karawang

\begin{tabular}{c} 
Jihan Akhidatussolihah \\
Ana Fitriana Poerana \\
Fardiah Oktariani Lubis \\
Fakultas Ilmu Sosial dan Politik, Universitas Singaperbangsa Karawang \\
Jl. HS Ronggowaluyo Karawang \\
jihanakhidatusoliha@ gmail.com, ana.fitriana@ fisip.unsika.ac.id, \\
fardiah.lubis@ fisip.unsika.ac.id \\
\hline Dikirim: 12 Januari 2021, Direvisi: 25Juni 2021, Diterima: 30 Juni 2021, \\
Terbit: 30 Juni 202. \\
Sitasi: Akhidatussolihah,Poerana.Lubis, (2021 Dramaturgi Media Sosial: \\
Fenomena Penggunaan Fake Account Instagram Pada Penggemar K-POP \\
Perempuan di Karawang. PRoMedia \\
Volume 7 (1), Juni 2021, hal 108- hal 136. \\
\hline
\end{tabular}

\begin{abstract}
Development of technology gives a significant impact in all areas, including communication. The emergence of new media or new media becomes a form of a media revolution that can facilitate people in the process of communication, one example is Instagram, launched in 2010, this app has a lot of features provided to support its user convenience. One of them is multiple account feature which was released in 2016, this feature raises the occurrence of a fake account usage phenomenon in Instagram app. Fake account Instagram or finstagram is interpreted as a non-real account, the multiple accounts feature allows Instagram users to access two accounts at once in one smartphone. This research uses qualitative research methods with dramaturgy theory, the primary data of researchers is the result of observing research objects and in-depth interviews with research subjects. Through this study the researchers found the result there are
\end{abstract}


PROMEDIA (PUBLIC RELATION DAN MEDIA KOMUNIKASI) ISSN2460-9633 Volume Ke-7 No. 1, 2021, Akhidatussolihah,dkk, Dramaturgi Media Sosial, hal 108-hal 136.

several reasons and the motivation of K-Pop fans who use fake account. There is a difference in account management and identity when using a fake account (back stage) and a real account (front stage), this is a form of impression management to get a good rating from other people.

\title{
Keywords: Dramaturgy, Fake Instagram Account, K-Pop Fans, Identity, Social Media
}

\begin{abstract}
Abstraksi
Perkembangan teknologi yang pesat memberikan perubahan yang signifikan di segala bidang, termasuk komunikasi. Munculnya media baru atau new media menjadi suatu bentuk dari revolusi media yang dapat memudahkan manusia dalam proses komunikasi, contohnya adalah Instagram, aplikasi yang resmi dirilis pada tahun 2010 ini memiliki banyak sekali fitur untuk mendukung kenyamanan pengunanya. Salah satunya adalah fitur mutiple account yang dirilis pada tahun 2016 lalu, adanya fitur ini memunculkan terjadinya fenomena penggunaan fake account di aplikasi Instagram. Fake Account Instagram atau Finstagram yang diartikan sebagai akun bukan sebenarnya atau palsu, fitur multiple account ini membuat para pengguna Instagram dapat mengakses lebih dari satu akun Instagram dalam satu smartphone. Penelitian ini menggunakan metode penelitian kualitatif dengan teori dramaturgi, data utama peneliti merupakan hasil observasi dan wawancara mendalam terhadap subjek penelitian. Peneliti menemukan hasil bahwa akan adanya beberapa tujuan yang dikemukakan oleh para penggemar $K$-Pop untuk menggunakan fake account. Dimana terdapat perbedaan dari segi tampilan akun dan identitas yang dipakai saat menggunakan akun palsu sebagai panggung belakang sedangkan akun asli sebagai panggung depan digunakan sebagai bentuk pengelolaan kesan untuk mendapat penilaian citra yang baik dimata orang lain.
\end{abstract}


PROMEDIA (PUBLIC RELATION DAN MEDIA KOMUNIKASI) ISSN2460-9633 Volume Ke-7 No. 1, 2021, Akhidatussolihah,dkk, Dramaturgi Media Sosial, hal 108-hal 136.

\section{Kata Kunci: Dramaturgi, Fake Instagram Account, Penggemar K-Pop, Identitas, Media Sosial}

\section{PENDAHULUAN}

Salah satu jenis media baru yang tengah populer adalah media sosial, Berdasarkan hasil riset oleh salah satu perusahaan marketing We Are Social yang bekerjasama dengan situs layanan media daring Hootsuite mengenai pemakaian internet dan juga media sosial di seluruh dunia, diketahui bahwa 4,4 miliar orang diseluruh dunia menggunakan internet. Dan dari 4,4 miliar orang tersebut, 3,5 miliar orang diantara aktif menggunakan media sosial, terlepas apapun media sosial yang digunakan.

Gambar.1 Hasil Penelitian Digital Around The World In 2019

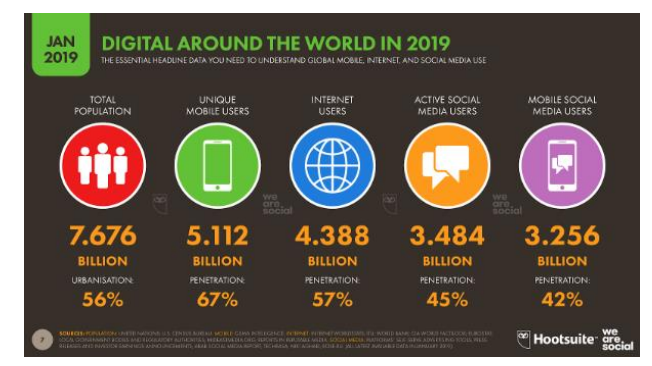

Sumber: website www.wearesocial.com

Dengan adanya hasil riset tersebut terbukti bahwa pengguna media sosial di seluruh dunia sangat besar, ini menandakan semakin menipisnya batas ruang dan waktu, semakin banyak fitur atau layanan khusus yang diberikan oleh setiap platform media sosial, menimbulkan banyak sekali 
PROMEDIA (PUBLIC RELATION DAN MEDIA KOMUNIKASI) ISSN2460-9633 Volume Ke-7 No. 1, 2021, Akhidatussolihah,dkk, Dramaturgi Media Sosial, hal 108-hal 136.

kemudahan yang didapat manusia. Mereka bebas mereprentasikan diri mereka di dunia virtualnya. Ingin menjadi apa dan bagaimana di dunia siber. Karena memang pada kenyataannya sangat banyak kasus yang membuktikan bahwa identitas dan tampilan kesan yang digunakan oleh setiap individu di dunia siber terdapat dua kemungkinan, yakni yang ditampilkan sama dengan kehidupan dan identitas aslinya atau bisa jadi berbeda atau buatan semata.

Instagram sendiri merupakan sebuah platform media sosial yang dapat digunakan oleh para penggunanya untuk berbagi foto dan video dengan sesama pengguna lainnya. Instagram menjadi sumber pemenuhan informasi bagi masyarakat, karena memang sudah banyak sekali akun - akun yang mejadikan informasi mengenai sosial, ekonomi, peristiwa terkini yang terjadi. Bahkan saat ini transaksi jual - beli pun marak terjadi di Instagram (online shop).

Banyaknya fitur yang di suguhkan oleh Instagram ini menarik minat penggunanya, seperti Stories, Direct, IGTV, Shopping, Search \& Explore. Hingga pada 8 Februari 2016 lalu, Instagram memberikan pemberitahuan di situs resminya bahwa mereka memiliki fitur terbaru yaitu mutiple account. Dengan adanya fitur ini para pengguna diperbolehkan untuk mengakses lebih dari satu akun hanya dalam satu perangkat tanpa harus melakukan logout. Hal ini pun menjadi faktor terbesar mengapa orang mempunyai fake account. 
PROMEDIA (PUBLIC RELATION DAN MEDIA KOMUNIKASI) ISSN2460-9633 Volume Ke-7 No. 1, 2021, Akhidatussolihah,dkk, Dramaturgi Media Sosial, hal 108-hal 136.

Instagram yang saat ini tengah populer tentu memberikan pengaruh yang besar terhadap para penggunanya, munculnya fenomena penggunaan Fake Account Instagram atau Finstagram yang pada awalnya digunakan oleh para remaja sebagai hiburan semata justru membentuk budaya virtual yang semakin besar.

Berdasarkan riset yang dilakukan oleh perusahaan Ghost Data, ditemukan fakta bahwa 95 juta dari 1 miliar akun di Instagram di dunia hanya akun palsu belaka. Pihak Instagram sendiri menyatakan rutin membersihkan jutaan akun palsu per Desember 2014. Dijelaskan bahwa akun palsu cenderung digunakan untuk mengikuti akun Instagram popular seperti akun selebriti, dan foto yang diunggah pun diperoleh dari situs web lain". (Agustin, www.liputan6.com: 2018).

Gambar.2 Data Penyebaran Fans K-Pop di Indonesia Tahun 2019

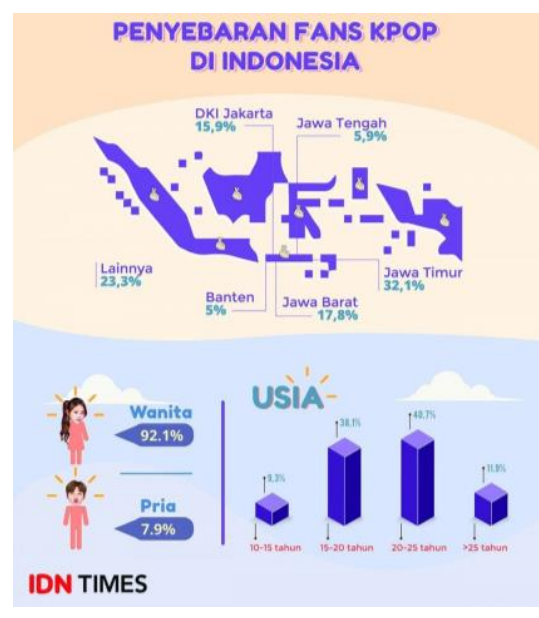

Sumber: website www.idntimes.com

Berdasarkan hasil riset tersebut, menunjukan bahwa dari total 580 koresponden, sebanyak $92,1 \%$ merupakan perempuan, 
PROMEDIA (PUBLIC RELATION DAN MEDIA KOMUNIKASI) ISSN2460-9633 Volume Ke-7 No. 1, 2021, Akhidatussolihah,dkk, Dramaturgi Media Sosial, hal 108-hal 136.

dan sisanya sebanyak 7,9\% merupakan laki - laki. Sehingga dapat ditarik kesimpulan bahwa mayoritas penggemar K-Pop di Indonesia adalah perempuan, dan peneliti menjadikannya sebagai pertimbangan untuk memilih perempuan sebagai subjek penelitian, dengan menambahkan kriteria seperti sudah menjadi penggemar K-Pop selama lebih dari 3 tahun, menggunakan instagram dan memiliki fake account minimal 2 tahun, serta tergabung dalam sebuah fandom atau perkumpulan penggemar idol tertentu.

Dalam fake account ini tidak semua orang dapat melihat unggahannya karena sebagian besar fake account bersifat rahasia sehingga di private. Identitas yang dicantumkan atau di pakai oleh akun ini dibuat berbeda jauh dari identitas asli penggunanya. Hal ini betujuan agar akun tersebut tidak mudah ditemukan oleh sembarang orang. tampilan fake account menggambarkan sisi lain dari sang pemilik akun, unggahan yang sering terlihat di fake account hanya berupa gambar tidak teratur atau acak, foto selebriti idola, dan gambar kutipan kalimat yang sang pemilik ingin diperlihatkan kepada orang - orang tertentu saja.

K-Pop atau Korean Pop sendiri merupakan salah satu produk dari budaya Korea Selatan yang populer berupa suatu jenis aliran music, K-Pop mulai masuk ke Indonesia pada tahun 2011, aktivitas komunikasi yang dilakukan oleh penggemar $K$ Pop di Indonesia lebih sering melalui beberapa platform media sosial khususnya Instagram dan Twitter, hal ini terjadi karena 
PROMEDIA (PUBLIC RELATION DAN MEDIA KOMUNIKASI) ISSN2460-9633 Volume Ke-7 No. 1, 2021, Akhidatussolihah,dkk, Dramaturgi Media Sosial, hal 108-hal 136.

jangkauan internet yang sangat luas sehingga memudahkan mereka untuk saling berinteraksi dengan penggemar lain yang tersebar di seluruh dunia (Valentina: 2013).

Pada kenyataanya fenomena penggunaan fake account memang marak di kalangan penggemar K-Pop. Saat peneliti melakukan pra penelitian untuk membuktikan kebenaran fenomena ini, ternyata dari 54 orang responden yang merupakan penggemar K-Pop, sebanyak 69,3\% mengaku menggunakan fake account dan $32,6 \%$ lainnya tidak memiliki fake account Instagram. Berdasarkan beberapa hasil riset dan pemaparan diatas, membuat peneliti tertarik untuk mendalami lebih lanjut mengenai fenomena penggunaan fake account Instagram di kalangan penggemar K-Pop perempuan tersebut.

\section{TINJAUAN PUSTAKA}

\section{A. Media Sosial}

Media sosial merupakan salah satu bentuk dari revolusi media, yang juga disebut juga sebagai media baru atau new media. Media sosial memiliki banyak kelebihan dibandingkan dengan media massa lain, media sosial memiliki banyak sekali jenis yang di suguhkan, memudahkan manusia untuk memenuhi kebutuhan informasi, untuk berinteraksi, atau hanya sekedar mencari hiburan saja.

Menurut Van Dijk, media sosial adalah sebuah platform yang memungkinkan eksistensi pengguna dengan memfasilitasi 
PROMEDIA (PUBLIC RELATION DAN MEDIA KOMUNIKASI) ISSN2460-9633 Volume Ke-7 No. 1, 2021, Akhidatussolihah,dkk, Dramaturgi Media Sosial, hal 108-hal 136.

mereka dalam beraktivitas ataupun berkolaborasi. Media sosial juga didefinisikan sebagai medium yang memungkinkan penggunanya merepresentasikan dirinya maupun berimteraksi, bekerjasama, berbagi, berkomunikasi dengan pengguna lain (Nasrullah, 2017: 11).

Jangkauan media sosial yang sangat luas sehingga dapat mengikis jarak antar pengguna membuat semakin disukai oleh masyarakat. Kemudahan yang terus disuguhkan dan kebebasan mengatur identitas diri yang diinginkan di media sosial membuat para penggunanya kadang lupa memanfaatkan dengan baik, terbukti dengan banyak tersebarnya hoax, hate speech, cyberbullying, dan kasus penipuan di media sosial.

\section{B. Identitas di Media Sosial}

Saat individu memutuskan untuk masuk dan memulai interaksi secara virtual melalui media sosial maka identitas diri mereka dapat dengan mudah dikreasikan, karena adanya kebebasan ini membuat para pengguna media sosial menjadi sangat leluasa mebentuk tampilan diri sesuai keinginannya di media sosial. Meskipun dalam beberapa kasus ditemui identitas di dunia maya yakni secara online yang tetap memiliki kesamaan dengan identitas di dunia nyatanya atau secara offline, namun tetap saja tidak sedikit individu yang masih tertarik dengan pilihan untuk membentuk identitas yang menampilkan sisi lain dari karakter di dunia nyata. Tak bisa dipungkiri bahwa pengaruh internet ini membawa perubahan besar yang berdampak pada 
PROMEDIA (PUBLIC RELATION DAN MEDIA KOMUNIKASI) ISSN2460-9633 Volume Ke-7 No. 1, 2021, Akhidatussolihah,dkk, Dramaturgi Media Sosial, hal 108-hal 136.

setiap individu menjadi berani membangun dan menkreasikan identitasnya di media sosial, tanpa peduli identitas tersebut asli atau tidak.

Menurut Jordan, terdapat dua kemungkinan yang dapat menggambarkan seperti apa tugas individu saat berinteraksi di media sosial, yaitu:

1. Melalui proses agar terhubung di media sosial, para pengguna harus login dengan prosedur yang ditetapkan sebelumnya, seperti menulis nama akun dan kata sandi, memberikan ijin akses ke email, ijin ke situs media sosial, dan ijin terhadap laman web lainnya milik pengguna. Setelah itu, individu akan memiliki ruang sebut saja their own individualized place, yang merupakan laman khusus atau rahasia yang hanya dapat diakses oleh individu tersebut, ini biasa disebut dengan pengaturan akun.

2. Dunia virtual memiliki kebebasan dan keterbukaan mengenai identitas diri, hal ini sekaligus mengarahkan bagaimana setiap individu menggolongkan dan membangun identitasnya di media siber.

Interaksi virtual ini yang membuat lahirnya self-definition dan self-invetion pada akhirnya. Karena identitas di media sosial sendiri memang bersifat cair sehingga setiap individu bebas mengkreasikan tampilan dirinya di media sosial agar menimbulkan kesan tertentu yang akan dilihat oleh pengguna lainnya. Dengan hasil dari proses kreasi tersebut yang akan 
PROMEDIA (PUBLIC RELATION DAN MEDIA KOMUNIKASI) ISSN2460-9633 Volume Ke-7 No. 1, 2021, Akhidatussolihah,dkk, Dramaturgi Media Sosial, hal 108-hal 136.

menjadi perwakilan individu dalam memainkan perannya ketika tengah berinteraksi di internet. Membuka dan menggunakan identitas yang sebenarnya secara jujur atau memilih untuk menggunakan identitas palsu saja merupakan dua pilihan yang dapat dilakukan. Selain itu, setiap ipengguna juga dibebaskan untuk mempunyai identitas lebih dari satu yang berbeda-beda karakteristik di setiap media sosialnya (Nasrullah, 2017:76-77).

\section{Teori Dramaturgi}

Erving Goffman mengemukakan teori dramaturgi pada tahun 1959, ia mengasumsikan bahwa setiap kegiatan individu dan interaksi yang terjadi dalam suatu situasi sosial di masyarakat disebut sebagai performa (performance) yang mana dalam dunia performa tersebut terdapat dua panggung, yaitu ada panggung depan (front region atau front stage) dan ada panggung belakang (back region atau back stage). Saat manusia berinteraksi, mereka akan secara otomatis memilih peran mana yang akan dijalankan. Panggung depan adalah segala sesuatu yang diperlihatkan saat mereka berinteraksi dengan orang lain atau bergabung dalam kelompok masyarakat. Sementara panggung belakang adalah tempat individu menyembunyikan identitas pribadinya atau sisi lain dari dirinya.

Menurut Goffman, ketika setiap individu saling berinteraksi, sebenarnya mereka ingin menampilkan suatu gambaran diri, citra atau image yang akan ditangkap oleh orang lain, ia menamai hal tersebut dengan istilah impression 
PROMEDIA (PUBLIC RELATION DAN MEDIA KOMUNIKASI) ISSN2460-9633 Volume Ke-7 No. 1, 2021, Akhidatussolihah,dkk, Dramaturgi Media Sosial, hal 108-hal 136.

management. Impression management merupakan cara yang dipakai individu guna membentuk kesan khusus, di saat tertentu individu akan mempresentasikan dirinya dalam bentuk tindakan atau dengan menggunakan atribut tertentu, seperti gaya berpakaian, cara berbicara, gaya tata rias, dan lainnya. Ketika tengah berinteraksi setiap individu akan mengontrol dirinya agar terlihat seperti apa yang dikehendakinya, hingga tanpa disadari orang lain yang merupakan lawan komunikasinya pun melakukan hal yang serupa. Sebab itulah sesungguhnya setiap orang melakukan pertunjukan untuk orang lain, manusia menjadi aktor dan mengatur dengan sedemikian rupa penampilannya agar membuahkan kesan positif dari penontonnya: "people are actors, structuring their performance to make impressions on audience" (Kuswarno, 2009: 116).

\section{METODOLOGI PENELITIAN}

\section{A. Jenis Penelitian}

Jenis penelitian yang digunakan dalam penelitian ini adalah penelitian kualitatif menggunakan pendekatan etnografi virtual dan teori dramaturgi milik Erving Goffman, penelitian kualitatif sendiri adalah metode penelitian yang memiliki fungsi untuk mengkaji fenomena disekitar yang di alami oleh subjek penelitian seperti mengenai sebuah perilaku, sebuah persepsi, atau motivasi dalam melakukan tindakan. Hasil data yang diperoleh kemudian akan di tampilkan kembali secara deskriptif 
PROMEDIA (PUBLIC RELATION DAN MEDIA KOMUNIKASI) ISSN2460-9633 Volume Ke-7 No. 1, 2021, Akhidatussolihah,dkk, Dramaturgi Media Sosial, hal 108-hal 136.

dalam bentuk kata-kata, data tersebut bisa berupa tulisan, ucapan secara lisan, dan perilaku secara langsung yang dilakukan subjek penelitian.

\section{B. Pengumpulan Data}

Data diperoleh dengan beberapa metode, seperti dijelaskan sebagai berikut:

1. Wawancara

Peneliti melakukan wawancara mendalam (indepth interview) terhadap informan yang dinilai memenuhi kriteria dan dapat memberikan jawaban atas rumusan masalah, hal ini bertujuan agar dapat diperolehnya data yang lebih dalam sehingga peneliti mencoba mendengarkan penjelasan dari sudut pandang orang pertama yang memiliki pengalaman.

2. Observasi

Observasi yang lakukan merupakan observasi jenis partisipasi pasif, yang dilakukan 2 hari kepada masing-masing informan.

Penelitian ini memakan waktu 3 bulan lamanya (MaretMei 2020), dan berlokasi di Kabupaten Karawang. sumber data yang digunakan oleh peneliti ada dua jenis, yakni data primer yang merupakan data mentah dari hasil wawancara dengan informan atau narasumber. Lalu ada data sekunder yang merupakan hasil dari berbagai catatan berupa tulisan, artikel ilmiah, buku - buku teori, dan lain sebagainya (Sujarweni, 2014: 73). 
PROMEDIA (PUBLIC RELATION DAN MEDIA KOMUNIKASI) ISSN2460-9633 Volume Ke-7 No. 1, 2021, Akhidatussolihah,dkk, Dramaturgi Media Sosial, hal 108-hal 136.

Informan dalam penelitian ini adalah para penggemar $K$ Pop yang lebih dari 2 tahun telah menggunakan Instagram dan memiliki fake account dan juga real account. Informan ini berjumlah 3 orang ini diwawancarai secara mendalam oleh peneliti untuk mengetahui alasan mengapa mereka memiliki lebih dari satu akun Instagram yang berbeda karakter.

\section{PEMBAHASAN}

Peneliti memilih beberapa orang yang dirasa dapat mewakili dan mampu menjawab semua pertanyaan penelitian mengenai fenomena ini, dan berikut adalah empat orang informan yang memiliki dua akun Instagram:

1. Tiara Satriavi, 20 tahun, 2 tahun menggnakan fake account, dari fandom NCTZen

2. Neni Nuraeni, 21 tahun, 3 tahun menggunakan fake account, dari fandom EXOL

3. Nur Komalasari, berusia 21 tahun, 3 tahun menggunakan fake account, dari fandom ABNEW

Ketika sesi wawancara mendalam oleh peneliti dilakukan kepada setiap informan atau partisipan, ditemukan hasil bahwa tujuan mereka memiliki fake account Instagram adalah sebagai berikut:

1. Untuk memenuhi kebutuhan informasi dan hiburan 
PROMEDIA (PUBLIC RELATION DAN MEDIA KOMUNIKASI) ISSN2460-9633 Volume Ke-7 No. 1, 2021, Akhidatussolihah,dkk, Dramaturgi Media Sosial, hal 108-hal 136.

Para informan yang merupakan penggemar budaya asing merasa sangat diuntungkan dengan menggunakan Instagram untuk mengetahui kabar terbaru mengenai sang idola di Korea Selatan sana, mereka merasa bahwa keinginan untuk memenuhi kebutuhan informasi mendorong mereka untuk aktif menggunakan media sosial Instagram tersebut.

"pake fake account emang buat seneng - seneng ajasih, stalking idola, cari infomasi, jadi nggak nyampah aja di akun pribadi yang asli" (Tiara, wawancara, Jumat 13 Maret 2020).

2. Melindungi identitas sebagai penggemar K-Pop Para informan memilih untuk menyembunyikan identitas aslinya saat menggunakan fake account, hal ini ditunjukan dengan private atau akunnya yang dikunci, nama penggunanya pun berbeda dengan nama asli mereka, mereka memilih untuk tidak berteman dengan orang yang mereka kenal di akun tersebut, foto atau video yang di unggah bukan merupakan foto asli mereka, namu foto idola mereka atau hanya foto acak. Mereka merasa berhak melindungi identitas pribadinya demi kenyamanan agar lebih bebas berekspresi saat menggunakan media sosial karna mereka menilai bahwa tidak semua orang menyukai hal-hal yang berhubungan dengan $K$-Pop. 
PROMEDIA (PUBLIC RELATION DAN MEDIA KOMUNIKASI) ISSN2460-9633 Volume Ke-7 No. 1, 2021, Akhidatussolihah,dkk, Dramaturgi Media Sosial, hal 108-hal 136.

“intinya ngga mau orang tau kalo aku sefanatik itu sama K-Pop, soalnya dulu sebelum pake fake account banyak yang ngatain halu sama freak" (Mala, wawancara, Minggu 15 Maret 2020).

3. Nyaman berinteraksi

Dalam penelitian ini para informan menggunakan fake account tentu bukan untuk berinteraksi dengan keluarga atau teman dunia nyatanya, melainkan khusus digunakan untuk berinteraksi dengan sesama penggemar K-Pop untuk saling bertukar informasi.

“cukup orang yang sepemahaman sama gua aja yang tau gua suka K-Pop, mangkannya gua bikin akun fake, disitu mau upload apa dan dengan caption apa juga aman aja nggak ada yang komen negatif" (Neni, wawancara, Minggu 29 Maret 2020).

\section{A. Analisis Panggung Depan (Front Stage)}

Tabel 1. Akun Asli Milik Informan

\begin{tabular}{ccc}
\hline No & Informan & Nama Akun \\
\hline 1. & Tiara & @ tiarasatriavi \\
\hline
\end{tabular}


PROMEDIA (PUBLIC RELATION DAN MEDIA KOMUNIKASI) ISSN2460-9633 Volume Ke-7 No. 1, 2021, Akhidatussolihah,dkk, Dramaturgi Media Sosial, hal 108-hal 136.

\begin{tabular}{ccc}
\hline No & Informan & Nama Akun \\
\hline 2. & Neni & @ neninuraeni \\
\hline 3. & Mala & @layayeah \\
\hline
\end{tabular}

Panggung depan atau front stage adalah bagian dari performa individu yang bertujuan agar kesan yang ditampilkan tetap dalam aturan umum dan tetap dapat didefinisikan dengan baik oleh mereka yang melihatnya. Dalam panggung depan ini terdapat proses mempersiapkan artibut untuk membentuk kesan atau bisa disebut pengaturan (setting). Dalam kasus ini, setting yang digunakan oleh para informan di real account Instagramnya adalah fitur yang memungkinkan mereka menggungah foto dan video sesuai dengan keinginan, didukung pula dengan fitur editing yang disediakan oleh Instagram untuk memotong, mengatur kontras hingga menambahkan filter yang ada.

Berikut beberapa tampilan personal front yang ditampilkan oleh para informan melalui real account-nya yaitu:

1. Jumlah Pengikut (Followers)

Para informan memperhatikan jumlah akun pengikut (followers) dan akun yang diikuti (following) yang ada pada akun asli Instagramnya. Mereka tidak suka jika jumlah following-nya lebih tinggi dibandingkan akun yang mengikuti followers-nya, mereka pun menyeleksi siapa 
PROMEDIA (PUBLIC RELATION DAN MEDIA KOMUNIKASI) ISSN2460-9633 Volume Ke-7 No. 1, 2021, Akhidatussolihah,dkk, Dramaturgi Media Sosial, hal 108-hal 136.

saja akun yang akan mereka ikuti balik agar angka followers dan following-nya tetap sesuai keinginan.

Gambar 3. Jumlah Followers dan Following Real Account Tiara

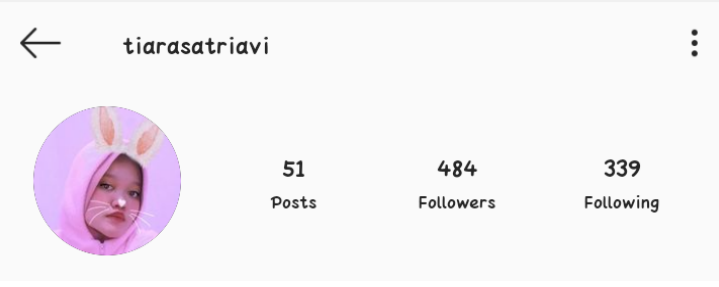

Sumber: www.instagram.com

2. Tampilan Unggahan (Feeds)

Di akun asli ini, para informan merasa perlu memperhatikan keindahan unggahan mereka, baik dari segi warna foto yang senada, bingai foto yang sama, dan juga keterangan unggahan yang mereka tulis dirasa perlu di perhatikan, sehingga tak jarang mereka harus menyeleksi mana saja foto atau video yang layak di unggah, unggahan mereka di akun ini berisikan kegiatan sehari-hari, seperti foto pribadi, foto dan video bersama teman dan keluarga tanpa menampilkan sedikit pun hal hal yang berkaitan dengan $K$-Pop walaupun mereka adalah penggemarnya. Mala mengatakan bahwa memang perlu memperhatikan komposisi feeds Instagramnya agar terlihat indah.

Gambar 4. Tampilan Real Account Mala 
PROMEDIA (PUBLIC RELATION DAN MEDIA KOMUNIKASI) ISSN2460-9633 Volume Ke-7 No. 1, 2021, Akhidatussolihah,dkk, Dramaturgi Media Sosial, hal 108-hal 136.

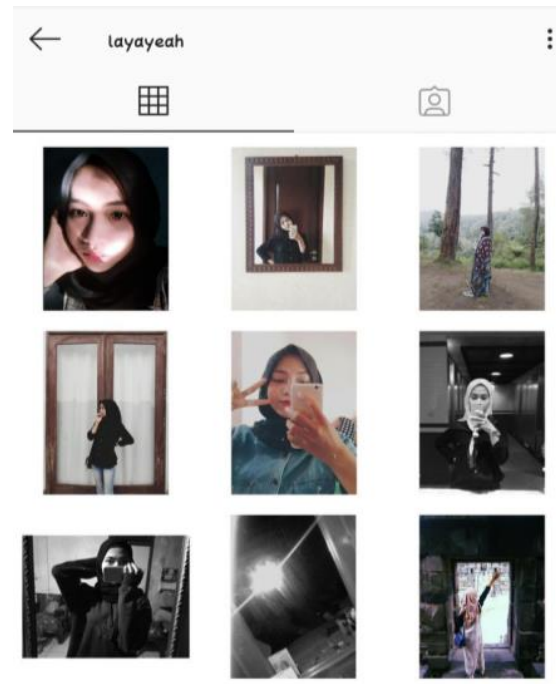

Sumber: www.instagram.com

\section{Nama Pengguna Akun (Username)}

Bagian pengaturan di akun media sosial kita tentu merupakan hak tersendiri untuk kita atur sedemikian rupa. Seperti halnya dengan para informan di penelitian ini, mereka memilih untuk memberikan nama real account mereka dengan nama asli atau nama yang berhubungan dengan diri mereka sendiri agar mudah ditemukan oleh orang yang mencari mereka, akun ini berisi unggahan mengenai kehidupan nyata para informan sehingga nama akunnya pun dibuat dengan tidak ada unsur K-Pop sama sekali,

Gambar 5. Nama Real Account Tiara 
PROMEDIA (PUBLIC RELATION DAN MEDIA KOMUNIKASI) ISSN2460-9633 Volume Ke-7 No. 1, 2021, Akhidatussolihah,dkk, Dramaturgi Media Sosial, hal 108-hal 136.

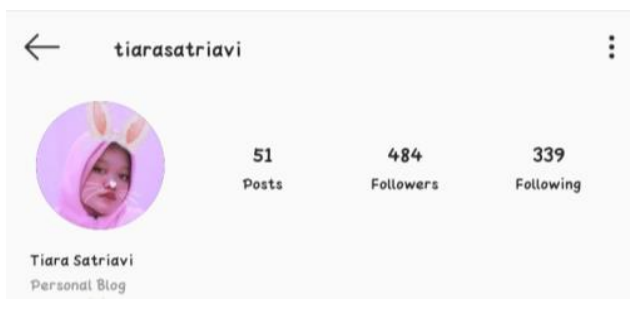

Sumber: $\underline{w w w . i n s t a g r a m . c o m}$

4. Gaya Menulis Komentar

Gaya menulis komentar saat menggunakan real account juga memiliki perbedaan daripada fake account, di akun ini para informan memilih perkataan yang akan mereka ketik karna dalam akun ini berisik teman dan keluarga yang tentu harus mereka jaga perasaannya, gaya penulisannya terkesan lebih rapih, mereka memilih untuk membangun kesan sebagai remaja ramah, lugu, bertutur baik, dan ceria.

Gambar 6. Komentar Real Account Neni

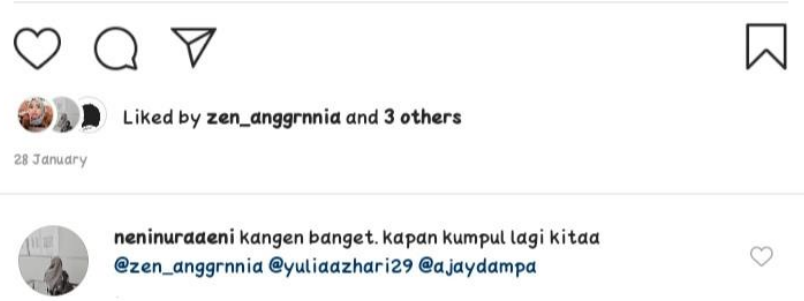

Sumber: www.instagram.com

\section{B. Analisis Panggung Belakang (Back Stage)}

Panggung belakang atau back stage merupakan tempat di mana individu menyembunyikan menjaga kerahasiannya tentang 
PROMEDIA (PUBLIC RELATION DAN MEDIA KOMUNIKASI) ISSN2460-9633 Volume Ke-7 No. 1, 2021, Akhidatussolihah,dkk, Dramaturgi Media Sosial, hal 108-hal 136.

identitas personal dan sisi lain dari dirinya, tempat dimana para aktor tak lagi memakai atributnya. Panggung belakang lebih bersifat rahasia, dan biasanya bersebrangan dengan panggung depan (front stage). Karena kerahasiaan inilah tidak boleh ada orang lain yang memasuki panggung belakang ini selain sang aktor, kecuali jika ada sesuatu yang mendesak dan penting. Dalam penelitian ini, fake account menjadi panggung belakang (back stage) para informan, tempat dimana mereka bebas menggungah dan menulis apa saja tentang K-Pop tanpa takut di komentari negatif oleh followers-nya.

Tabel 2. Akun Palsu Milik Informan

\begin{tabular}{lcc}
\hline No & Informan & Nama Akun \\
\hline 1. & Tiara & @kimnotlee \\
\hline 2. & Neni & @ nnki.m \\
\hline 3. & Mala & @justanali3n
\end{tabular}

\section{Jumlah Pengikut (Followers)}

Jika di real account para informan lebih memperhatikan jumlah pengikut (followers) dan akun yang diikuti (following) maka pada fake account adalah sebaliknya, mereka tidak memperdulikan hal itu, mereka berpendapat bahwa tidak penting jumlah followers di fake account, karna fungsi fake account sendiri bukan sebagai alat 
PROMEDIA (PUBLIC RELATION DAN MEDIA KOMUNIKASI) ISSN2460-9633 Volume Ke-7 No. 1, 2021, Akhidatussolihah,dkk, Dramaturgi Media Sosial, hal 108-hal 136.

eksistensi utama mereka, dan akun ini juga disembunyikan, jadi mereka merasa tidak butuh pengakuan dan pujian dari siapapun atas apa yang terjadi di fake account-nya.

"aku gunain fake account buat nge-follow akun fanbase gitu, buat ngiikutin online shop yang jual marchandise K-Pop, trus buat nge-follow idol sama nonton live Instagramnya, jadi ga perlu followers" (Tiara, wawancara, Jumat 13 Maret 2020).

Gambar 7. Jumlah Followers dan Following Fake Account Tiara

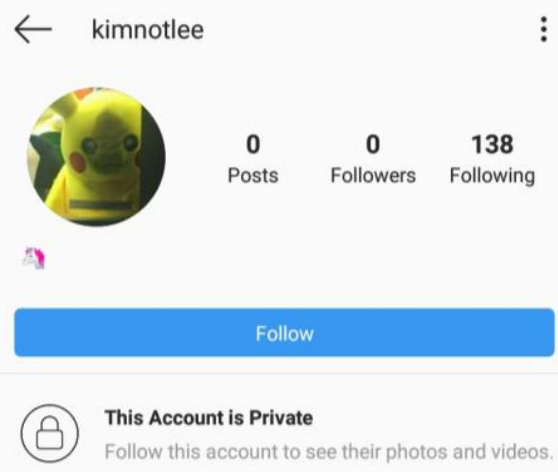

Sumber: www.instagram.com

2. Tampilan Unggahan (Feeds)

Tampilan unggahan fake account para informan, tidak terlalu diperhatikan seperti real account, tidak ada foto 
PROMEDIA (PUBLIC RELATION DAN MEDIA KOMUNIKASI) ISSN2460-9633 Volume Ke-7 No. 1, 2021, Akhidatussolihah,dkk, Dramaturgi Media Sosial, hal 108-hal 136.

pribadi, hanya berisi foto sang idola, bahkan Tiara tidak memiliki postingan apapun di fake account-nya.

Gambar 8. Tampilan Fake Account Mala

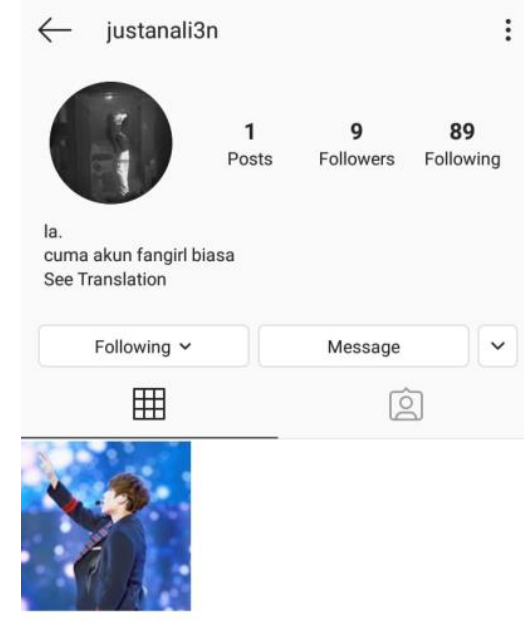

Sumber: www.instagram.com

Menurut mereka hal tersebut memang tidak perlu mengingat sedikitnya atau bahkan tidak ada pengikut (followers) yang akan melihat. Para informan merasa tidak dituntut untuk terus meng-update tampilan akunnya, karna akun tersebut memang hanya untuk dirinya sendiri. “emang nggak pernah posting di feed, paling cuma di story doang sering. karena emang dipake buat cari informasi doang sih" (Mala, wawancara, Minggu 15 Maret 2020).

\section{Nama Pengguna Akun (Username)}


PROMEDIA (PUBLIC RELATION DAN MEDIA KOMUNIKASI) ISSN2460-9633 Volume Ke-7 No. 1, 2021, Akhidatussolihah,dkk, Dramaturgi Media Sosial, hal 108-hal 136.

Jika di real account para informan memilih untuk menggunakan nama asli mereka, lain hal nya dengan fake account mereka, di akun ini mereka tidak mencantumkan nama asli mereka yang dapat menggambarkan identitasnya. Mala dan Neni memilih untuk menggunakan nama akun dengan mencantumkan marga sang idola seperti Kim dan Lee, sedangkan Mala memilih memakai nama yang pernah terfikir dan ia menyukainya.

Gambar 9. Nama Fake Account Tiara

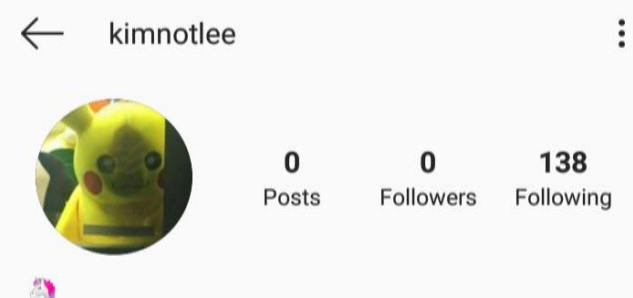

Sumber: www.instagram.com

4. Gaya Menulis Komentar

Di fake account, ketika para informan menulis komentar mereka akan menggunakan bahasa yang lebih beragam, mulai dari bahasa indonesia, sedikit istilah korea, ataupun bahasa inggris. Gaya penulisan yang mereka pakai terkesan berlebihan, apa adanya, frontal, dan lebih ekspresif, msialnya dengan menggunakan banyak emoticon. Berikut 
PROMEDIA (PUBLIC RELATION DAN MEDIA KOMUNIKASI) ISSN2460-9633 Volume Ke-7 No. 1, 2021, Akhidatussolihah,dkk, Dramaturgi Media Sosial, hal 108-hal 136.

adalah contoh komentar yang ditulis Neni pada unggahan Kai EXO.

Gambar 10. Komentar Fake Account Neni

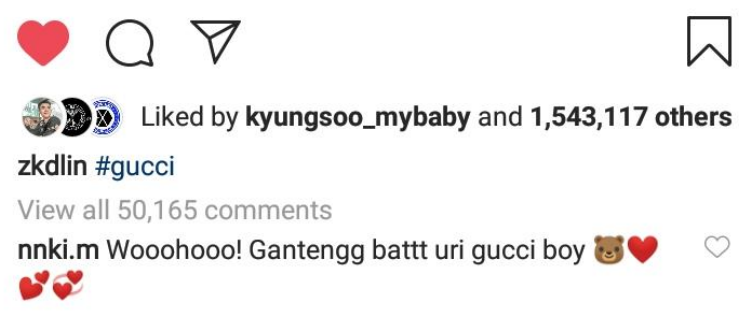

Sumber: www.instagram.com

\section{Analisis Dramaturgi}

Pengelolaan kesan atau impression management ini merupakan salah satu istilah yang dikemukakan oleh Goffman, pada kenyataannya memang banyak terjadi kasus dimana setiap individu ingin dinilai dan memiliki citra yang baik di depan orang lain, manusia selalu ingin menampilkan sisi terbaiknya pada orang lain, namun tak bisa dipungkiri bahwa tidak ada manusia yang sempurna, sehingga muncul panggung bagian depan (front stage) sebagai tempat pentas dan panggung bangian belakang (back stage) sebagai tempat beristirahat sang aktor dari perannya.

Panggung yang dimaksud disini bukan panggung secara fisik yang digunakan untuk sebuah pertujukan semata. Instagram 
PROMEDIA (PUBLIC RELATION DAN MEDIA KOMUNIKASI) ISSN2460-9633 Volume Ke-7 No. 1, 2021, Akhidatussolihah,dkk, Dramaturgi Media Sosial, hal 108-hal 136.

sendiri bisa dikatakan sebagai panggung para informan, dimana dengan banyaknya fitur yang dimiliki membuat para penggunanya semakin leluasa mengkreasikan tampilan dirinya di Instagram, sehingga dapat membentuk kesan yang sesuai dengan keinginan.

Dalam penelitian ini, peneliti dapat mengetahui bahwa akun asli (real account) para informan merupakan panggung depan mereka, menjadikan akun ini sebagai ajang eksistensi diri. Dengan memperhatikan tampilan dan jumlah pengikut di Instagram mereka mengunggah kesehariannya, lalu digunakan untuk berinteraksi dengan teman dan keluarga. Di panggung depan ini mereka membuat segala sesuatu tindakannya terstruktur agar sesuai dengan norma di masyarakat, melalui unggahan foto dan video nya mereka ingin menampilkan kesan yang positif, bukan kesan sebagai penggemar K-Pop yang fanatik atau berlebihan, tetapi kesan bahwa mereka adalah para gadis yang ceria, lugu, ramah, menyukai keindahan, bertutur kata baik, dan memiliki banyak teman.

Sedangkan di akun palsu (fake account) Instagramnya, mereka membuat sebagai tempat yang paling dijaga kerahasiannya, Tiara mengatakan bahwa akun ini merupakan tempat ia menujukan sisi yang terjujur dari dirinya. Tempat mereka membebaskan diri untuk melakukan segala sesuatu termasuk mengakui dan menunjukan diri mereka sebagai penggemar K-Pop yang setiap hari mengunggah tentang sang 
PROMEDIA (PUBLIC RELATION DAN MEDIA KOMUNIKASI) ISSN2460-9633 Volume Ke-7 No. 1, 2021, Akhidatussolihah,dkk, Dramaturgi Media Sosial, hal 108-hal 136.

idola, menulis komentar dengan kalimat berlebihan di unggahan idola, terlibat perselisihan dan debat antar penggemar lain di media sosial (fanwar).

Fake account ini selalu di private oleh para informan, hanya sesama penggemar K-Pop saja yang diperbolehkan untuk mengikuti akun tersebut, mereka menilai bahwa akan lebih nyaman jika mereka hanya berinteraksi dengan orang yang memiliki kesukaan yang sama, dan mereka pun mengatakan bahwa tujuan utama membuat fake account adalah untuk menghindari orang - orang yang tidak menyukai K-Pop.

Nama yang dipakai untuk fake account para informan pun dibuat sedemikian rupa dan jauh dari nama asli mereka sebenarnya berbanding terbalik dengan real account yang memakai nama asli. Para informan merasa memang sangat perlu menyembunyikan identitas diri mereka di fake account, selain dari nama akun yang disamarkan, mereka juga tak pernah mengunggah foto asli wajah mereka. Akun tersebut sepenuhnya hanya dijadikan sebagai akun untuk mengunggah segala sesuatu yang berkaitan dengan $K$-Pop.

Karena pengikut di akun asli (real account) mereka lebih banyak, maka para informan lebih memilih untuk mempertahan kesan yang baik agar terhidar dari komentar negatif atau kritikan. Pengikut real account mereka adalah teman dan keluarga, sedangkan fake account-nya tak memiliki pengikut sehingga mereka merasa lebih bebas untuk berekspresi tanpa takut akan 
PROMEDIA (PUBLIC RELATION DAN MEDIA KOMUNIKASI) ISSN2460-9633 Volume Ke-7 No. 1, 2021, Akhidatussolihah,dkk, Dramaturgi Media Sosial, hal 108-hal 136.

kritikan orang lain, kalaupun ada yang mengikuti fake account mereka, bisa dipastikan mereka adalah penggemar $K$-Pop juga. Karena sisi lain dari diri para informan yang merupakan penggemar K-Pop dan mengenai fake account nya yang selalu di private, membuat peneliti menyimpulkan bahwa fake account yang mereka gunakan merupakan panggung belakang (back stage), dimana mereka tidak ingin orang lain yang tidak dikehendaki dan diijinkan dapat memasukinya.

\section{KESIMPULAN}

Instagram yang saat ini tengah menjadi aplikasi media sosial terpopuler, membuat setiap penggunanya saling berlomba untuk menujukan eksistensi dirinya, dengan berbagai macam fitur yang ada mereka berusaha untuk menampilkan citra yang baik terhadap dirinya melalui akun Instagramnya. Para pengguna Instagram sadar akan pentingnya penilaian orang lain terhadap tampilan media sosial yang akan merepresentasikan dirinya.

Namun tuntutan terus - menerus untuk mengikuti standar yang di tetapkan oleh diri sendiri untuk membentuk citra dan kesan yang baik membuat para pengguna bosan dan ingin menampilkan sisi lain dari dirinya melalui akun lain yang memiliki karakter berbeda.

Para informan merasa lebih nyaman menggunakan fake account Instagram karena identitas asli nya tersembunyi dan orang yang berinteraksi dengan mereka saat menggunakan fake 
PROMEDIA (PUBLIC RELATION DAN MEDIA KOMUNIKASI) ISSN2460-9633 Volume Ke-7 No. 1, 2021, Akhidatussolihah,dkk, Dramaturgi Media Sosial, hal 108-hal 136.

account adalah orang yang memiliki kesukaan yang sama yaitu penggemar K-Pop juga, sehingga mereka merasa menemukan tempat yang tepat dibandingkan saat menggunakan real accountnya.

\section{DAFTAR PUSTAKA}

Kuswarno, E. 2009. Fenomenologi: Konsepsi, Pedoman dan Contoh Penelitian. Bandung: Widya Padjajaran.

Lastriani. 2018. Fanwar: Perang Antar Fans Idol K-Pop di Media Sosial. Jurnal Emik, Vol 1 No 1, 87-100. Retrieved Mey 6, 2020, from http://ejournals.umma.ac.id/index.php/emik/article/downloa $\mathrm{d} / 46 / 68$

Nasrullah, R. 2017. Media Sosial: Perspektif Komunikasi Budaya dan Sosioteknologi. Bandung: Simbiosa Rekatama Media.

Nasrullah, R. 2018. Etnografi Virtual. Bandung: Simbiosa Rekatama Media.

Rakhmat, J. 2005. Psikologi Komunikasi. Bandung: Remaja Rosdakarya.

Sujarweni, V. 2014. Metode Penelitian: Lengkap, Praktis dan Mudah di Pahami. Yogyakarta: Pustaka Baru Press.

Triadanti. 2019. Jadi Gaya Hidup Benarkan Fans KPop Kaya Raya atau Cuma Modal Kuota?. Retrieved June 20, 2020, from Idn Times: https://www.idntimes.com/hype/entertainment/amp/danti/ja di-gaya-hidup-benarkah-fans-kpop-kaya-raya-atau-cumamodal-kuota

Valentina, R. I. (2013). Gelombang Globalisasi Ala Korea Selatan. Jurnal Pemikiran Sosiologi, Vol 2, No 2, 71-86. doi:10.22146/jps.v2i2.30017

Wardani, A. 2018. Instagram di Susupi 95 Juta Akun Palsu. 
PROMEDIA (PUBLIC RELATION DAN MEDIA KOMUNIKASI) ISSN2460-9633 Volume Ke-7 No. 1, 2021, Akhidatussolihah,dkk, Dramaturgi Media Sosial, hal 108-hal 136.

Retrieved July 10, 2020, from Liputan 6: https://m.liputan6.com/tekno/read/3595223/duh-instagramdisusupi-95-juta-akun

We Are Social, Hootsuite. 2019. Global Digital Report 2019.

Retrieved March 2, 2020, from We Are Social:

https://wearesocial.com/global-digital-report-2019

https://www.instagram.com 